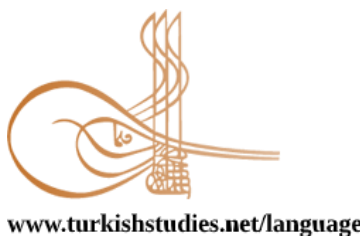

Turkish Studies - Language and Literature

\title{
Yedi İklim C1 ve C2 Düzeyi Ders Kitaplarındaki Dinleme Metinlerinde Yer Alan Değerler
}

\author{
Values in Listening Texts in the Books of Yedi Iklim C1 and C2 Level Textbooks
}

\author{
Alpaslan Okur* - Erhan Çapoğlu** - Alena Dhahi**
}

\begin{abstract}
Language is one of the most important tools for people to communicate with each other. Today, with the rapid advancement of technology, it has become easier for people from far away to communicate with each other. In this way, the increase in the usage areas of the language has increased the importance of language learning and language teaching. Language teaching is to teach not only the grammar rules of a language, but also the culture to which that language belongs. Divanü Lügati, which is the first source about teaching Turkish to be included in language teaching in its culture, is a method that has been used since Turkish. One of the most important elements of the concept of culture is value. The concept of value is in the Contemporary Dictionary of the Turkish Language Association (2019), "The whole of material and spiritual elements that includes the social, cultural, economic and scientific values of a nation." It was defined as. This definition shows that values are the mirror of society. Because when looking at the values of a society, an idea about that society can be reached. In this study, the values in the listening texts in Yedi Climates C1 and C2 level textbooks used in teaching Turkish to foreigners were investigated. Twenty-seven listening texts were analyzed in both textbooks, a total of 54 listening texts. In the $\mathrm{C} 1$ level book, a total of 29 values were found in 13 value titles, and it was seen that the most included value was "diligence". In the $\mathrm{C} 2$ level book, a total of 34 values were found in 15 different value titles, and it was seen that the most included value was "human love".
\end{abstract}

Structured Abstract: Language is one of the most important tools for people to express themselves, think and engage with other people. The language of a society is the most important element that enables us to understand that society. Today, it is seen that people feel the need to learn languages due to their various situations. People go to places where different languages are spoken, both for visiting, for education and for work. This situation reveals the importance of language learning and language teaching. In recent years, education, travel and education etc. for foreigners in our country. It is a center of attraction for occasions. In language teaching,

\footnotetext{
* Prof. Dr. Sakarya Üniversitesi Eğitim Fakültesi, Türkçe ve Sosyal Bilimler Eğitimi

Prof. Dr., Sakarya University, Faculty of Education, Department of Social Sciences and Turkish Education ORCID 0000-0002-2868-063X

alpaslanokur@gmail.com

** Doktora Öğrencisi, Sakarya Üniversitesi, Eğitim Bilimleri Enstitüsü

PhD. Student, Sakarya University, Institute of Educational Sciences

ORCID 0000-0001-5154-7856

capoglu.erhan@hotmail.com

** Doktora Öğrencisi, Sakarya Üniversitesi, Eğitim Bilimleri Enstitüsü

PhD. Student, Sakarya University Institute of Educational Sciences

ORCID 0000-0003-0553-5840

helen1590@yandex.ru

Cite as/ Atıf: Okur, A., Çapoğlu, E. \& Dhahi, A. (2020). Yedi İklim C1 ve C2 düzeyi kitaplarındaki dinleme metinlerinde yer alan değerler. Turkish Studies - Language, 15(3), 1369-1378. https://dx.doi.org/10.47845/TurkishStudies.44746

Received/Geliş: 01 July/Temmuz 2020

Accepted/Kabul: 27 September/Eylül 2020

Copyright $($ INTAC LTD, Turkey

Checked by plagiarism software

Published/Yayın: 30 September/Eylül 2020

CC BY-NC 4.0
} 
transferring the language and culture of that language is a method used since the first work accepted in the teaching of Turkish, Dîvânu Lugâti't-Türk. As a result of this cultural transfer, not only the grammar rules of that language, but also the culture and logic of those who speak it.

"Values" are the basis of these cultural transfer processes. Values are the mirror of a society. Just as in the mirror, if a person sees his own image, the values of a society are seen and the copy of that society is seen. Values are tools that control society and control the movements of people living in that community. The values of a society give us clues about that society.

The use of values in many areas as a concept has made it difficult to make a separate classification. Studies on teaching Turkish to foreigners should start with the example of Dîvânu Lugâti-Türk in the past, and the various materials used in trainings continued in many parts of the world through certain institutions, organizations and centers should also contain certain values. In this study, it is aimed to determine the values in the listening texts in the books of Seven Climate $\mathrm{C} 1$ and $\mathrm{C} 2$, one of the sources used in the process of teaching Turkish to foreigners. One of the main reasons for the study of the listening texts in the study is that the studies on listening, which is one of the four learning areas of the language, are insufficient and the value analysis studies are mostly done through reading texts. This study is the first study in the field to examine the values in the listening texts in the books used in Turkish education for foreigners.

Listening texts in C1 and C2 level textbooks prepared by Yunus Emre Institute were used in the study. In these two levels, there are 27 listening texts and 54 listening texts in total were examined. These texts were examined by experts according to the "Value Analysis Form" (DIF) and it was tried to determine what values the listening texts contain. Values, from Güngör's (1993) value classification, Rokeach's (1973) vehicle values and purpose values table, while the Value Analysis Form (DIF) developed by Çapoğlu(2014) was created. form was used. Cronbach Alpha internal consistency coefficient was determined as 0.768 for the value evaluation form. The titles of value in the Value Assessment Form (DIF) are: hospitality, benevolence, tolerance, compliance with social rules, compliance with etiquette, cultural awareness, family awareness, religious consciousness, moral awareness, honesty, integrity, courage, sensitivity, hardworking, human love, love of nature, love of animals, respect for elders, respect for Turkish elders, national consciousness, language awareness, citizenship awareness, democracy rights and freedoms, rationality, frugality and peace. In validity studies, the items in the form were examined by teachers.

In the $\mathrm{C} 1$ level textbook, a total of 29 values were found in 27 texts, and it was observed that the highest value in the texts was "diligence". Minimum values include: hospitality, compliance with etiquette, respect for Turkish elders, patriotism and national consciousness. As can be seen in the table, there are 13 different value titles. Values in 27 texts are given in C2 level textbook. A total of 34 values were found in 27 texts and it was seen that the most included value was "human love". The least values included are: awareness of responsibility, benevolence, respect for Turkish elders, tolerance, compliance with social rules, honesty, patriotism and rationality. As can be seen in the table, 15 different value titles can be seen. This is a desired situation in the books. A total of 54 listening texts were examined at two different levels and a total of 63 values were found in 28 different titles. The most common values are cultural awareness, human love and diligence. It was observed that the values in the listening texts examined were in line with the value classifications mentioned in the theoretical framework. In the future studies, the values in the listening texts in different textbooks can be examined. In this study, the values were examined according to the opinions of the experts. These values can also be examined by students. In addition, the frequency of values in different texts can be examined.

Keywords: Turkish Education, Language teaching, Language, Culture, Values,

Öz: Dil, insanların birbirleriyle iletişim kurmalarını sağlayan en önemli araçlardan biridir. Günümüzde teknolojinin de hızlı bir şekilde ilerlemesiyle birlikte çok uzak noktalardaki insanların bile birbirleriyle iletişim kurmaları kolaylaşmıştır. Bu şekilde dilin kullanım alanlarının artması, dil öğreniminin ve dil öğretiminin de önemini arttırmıştır. Dil öğretimi, bir dilin sadece dil bilgisi kurallarını öğretmek değil, o dilin mensup olduğu kültürünü de öğretmektir. Kültüründe dil öğretiminin içinde yer alması Türkçenin öğretimi ile ilgili ilk kaynak olan Dîvânu Lugâti’t-Türk’ten beri kullanılan bir yöntemdir. Kültür kavramının en önemli unsurlarından biri de değerdir. Değer kavramı Türk Dil Kurumuna ait Güncel Sözlük’te (2019) “Bir ulusun sahip olduğu sosyal, kültürel, ekonomik ve bilimsel değerlerini kapsayan maddi ve manevi ögeler bütünü.” olarak tanımlanmıştır.

Turkish Studies - Language, 15(3) 
Bu tanım, değerlerin toplumun aynası olduğunu göstermektedir. Çünkü bir toplumun değerlerine bakıldığında o toplum hakkında bir fikre ulaşılabilir. Bu çalışmada yabancılara Türkçe öğretiminde kullanılan Yedi İklim C1 ve C2 düzeyi ders kitaplarında yer alan dinleme metinlerindeki değerler araştırılmıştır. Her iki ders kitabında da yirmi yedişer, toplamda 54 tane dinleme metni incelenmiştir. C1 düzeyindeki kitapta 13 değer başlığında toplam 29 tane değer bulunmuş olup en fazla yer verilen değerin "çalışkanlık" olduğu görülmüştür. C2 düzeyindeki kitapta ise 15 farklı değer başlığında toplam 34 tane değer bulunmuş olup en fazla yer verilen değerin "insan sevgisi” olduğu görülmüştür.

Anahtar Kelimeler: Türkçe öğretimi, Dil öğretimi, Dil, Kültür, Değerler

Dil sözcüğü, TDK’ye ait Güncel Türkçe Sözlük (2019)’te “İnsanların düşündüklerini ve duyduklarını bildirmek için kelimelerle veya işaretlerle yaptıkları anlaşma, lisan, zeban" olarak tanımlanır. Erdal'a (2018: 83) göre dil, insanların birbirleriyle iletişim kurmalarını sağlayan, onları düşündüren, çevresini algılamasını sağlayan, konuşarak kendini ifade etmesine yarayan bir araçtır. Özellikle teknolojinin gelişmesiyle birlikte farklı yerlerde yaşayan ve farklı dillerde konuşan insanların birbiriyle iletişim hâlinde olmaları kaçınılmaz bir gerçektir. Bu durum, dil öğrenmenin ve dil öğretmenin önemini ortaya koymaktadır. Dil öğretmede dil ile birlikte o dilin kültürünü de aktarmak, Türkçenin öğretiminde bilinen ilk eser kabul edilen Dîvânu Lugâti't-Türk'ten itibaren kullanılan bir yöntemdir (Boztilki, 2018: 756). Bu kültür aktarımı neticesinde o dilin sadece dil bilgisi kuralları değil, o dili konuşanların kültürü kavratılmaktadır. Bu kültür aktarım süreçlerinin temelinde "değerler" gelmektedir. Değerler bir toplumun kültürünü yansitan ve o toplumu gösteren en önemli ögelerden biridir. Dil öğretimiyle beraber kültür aktarımı da yapılacaksa kültür aktarımın ilk aşaması değerler olmalıdır. Bu çalışmada yabancılara Türkçe öğretimi sürecinde kullanılan kaynaklardan biri olan Yedi İklim C1 ve C2 düzeyi kitaplarındaki dinleme metinlerinde yer alan değerlerin tespit edilmesi amaçlanmıştır. Çalışmada dinleme metinlerinin incelenmesinin temel nedenlerinden biri, alan yazına bakıldığında yabancılara Türkçe öğretimi alanında yapılmış olan değer inceleme araştırmalarında dört temel öğrenme alanından biri olan "dinleme" hakkında yapılan çalışmaların yetersiz olmasıdır. Bu çalışma, yabancılara Türkçe öğretiminde kullanılan kitaplarda yer alan dinleme metinlerindeki değerleri inceleme açısından alanda yapılmış ilk çalışmadır.

\section{Değerler}

Dünyada hızlı bir değişimin olduğu görülmektedir. Her ne kadar bu değişimin, hayatımıza getirdiği birçok yenilik ve kolaylık varsa da bazı durumlar için olumsuz etkileri bulunmaktadır. Değerler bir toplumun yapı taşlarıdır ve toplumun benliğini gösteren, o toplumu anlamaya yarayan birer rehberdir. Hilmi Ziya Ülken (1986'dan aktaran Akyol Gürler ve Aydın, 2014: 17)'e göre toplum, maddi ve manevi olarak insanları kuşatan bütün iş, karakter, inanç ve değerler sistemidir. Bu durum toplumun oluşumunda değerlerin önemini ortaya koymaktadır. Değer kavramı birçok bilim dalında kullanılmaktadır. Bu durum, değer kavramının müstakil bir tanımının yapılmasını zorlaştırmıştır. Değerler, bir toplumu yansıtan ayna ve o toplumun özelliklerini gösteren birer rehberdir. Nasıl ki bilinmeyen bir yere gidildiğinde o yere ait bir rehber, o yeri anlamay kolaylaştıracaksa bir toplumu anlamak için de değerler o toplumu anlamamızı kolaylaştıracaktır.

Akyol Gürler ve Aydın'a (2014: 7) göre değerler; tarihi birikimlerden oluşan, üzerinde görüş birliği bulunan, sosyal hayatı düzenleyen ve kontrol eden unsurlardır. Değerler üzerine farklı alanlarda yapılmış çalışmalar değerler üzerinde çeşitli sınıflamaların ve ayrımların yapılması gereğini ortaya koymuştur. Bunlar: Spranger, Rokeach ve Schwartz'ın değer sinıflamalarıdır. Ayrıca geçmiş yıllarda Hilmi Ziya Ülken, Takiyettin Mengüşoğlu'nun değer sınıflandırmaları da bulunmaktadır (Çapoğlu, 2014: 2). "İnsan Felsefesi" adlı eserinde Takiyettin Mengüşoğlu, değerleri üç ana başlıkta incelemiş olup bunlar: yüksek değerler, araç değerler ve davranış değerleridir. Yüksek değerler başlığında şu değerler bulunmaktadır: iyi, şeref, güven, adalet, hak, dürüstlük, saflık, masumluk, doğruluk, bilgi ve sevgi. Araç değerlerde; kuşku, yarar, çıkar, kıskançlık çekememezlik 
ve her türlü maddesel değerler (para, mülkiyet vb.) yer alır. En son davranış değerleri olarak da ulusların geleneklerinde bulunan değerler ve görgü kuralları yer almaktadır (Çapoğlu, 2014: 11).

Eduard Spranger'in oluşturduğu değer grupları daha sonra Allport ve arkadaşları tarafindan tekrar düzenlenmiştir. Bu düzenlemede altı temel değer belirtilmiştir, bunlar: politik değer, sosyal değer, estetik değer, ekonomik değer, bilimsel değer ve dini değerdir (Akbaş, 2004: 55). Bir diğer değer sınıflandırması ise Milton Rokeach'e aittir. Rokeach, değerleri "gaye değerler" ve "vasıta değerler" olmak üzere iki başlık altında incelemiştir (Güngör, 2000: 85). Gaye değerler; barış içinde bir dünya, bilgelik, başarılı olma, aile güvenliği, sosyal kabul, dini olgunluk, eşitlik, gerçekler dünyası, güzellikler dünyası, heyecan verici bir yaşam, iç huzur, kendine saygı, mutluluk, gerçek dostluk, özgürlük, rahat bir yaşam, ulusal güvenlik ve zevktir. Vasıta değerler ise bağımsız olma, bağışlayıcılık, cesaret, dürüstlük, entelektüellik, geniş görüşlülük, itaatkârlık, hırslılık, kendini kontrol, kibarlık, kendine hâkim olma, mantıklılık, neşelilik, sevecenlik, sorumluluk sahibi olma, temizlik, yaratıcılık ve yardımseverliktir. Schwartz ise Rokeach'nın değer sınıflaması üstünde çalışmış ve 10 temel değer tipi olarak gruplayıp toplam 56 değer belirtmiştir. (Kuşdil ve Kâğıtçıbaşı, 2000: 60-61).

\section{Değerler ve Dil Öğretimi}

Birey yabancı bir dili öğrenmeye başladığında o dilin kültürel kavramlarıyla da karşılaşmaktadır. Kalfa'ya (2013: 97) göre dil öğretimi aynı zamanda bir kültür öğretimidir ve modern dil öğretim yaklaşımlarında dil öğretiminin yanında o dili kullanan insanların kültürünün de öğretiminin başarıya ulaşmada önemli olduğu belirtilmiş̧ir. Her kültürün ona kendi kimliğini kazandıran, kendine özgü bir dili vardır. Dilin içinde kültürün bütün özellikleri ve tarihsel, toplumsal birikimleri bulunur. (Okur ve Keskin, 2013: 1623). Bu durum, yabanc1 dil öğrenen kişinin o dili öğrenmek için sadece o dilin kurallarını öğrenmesinin yeterli olamayacağını göstermektedir. Çünkü dil ait olduğu kültürü yansitmaktadır. Kramsch (1993'ten akt. Okur ve Keskin, 2013: 1623)'e göre "Dil öğrenmek o kültürü tanımaktır." İşcan ve Yassıtaş (2018) da yabancı bir dilin, beraberinde yabancı bir kültür getirdiğini ve bireylerin dili daha iyi anlayabilmeleri için dilini öğrendikleri ülke ile ilgili kültürel özelliklerin öğrenilmesinin oldukça önemli olduğunu belirtir.

Tomalin ve Stempleski (1993:89’tan akt. Okur ve Keskin, 2013: 1624) kültür ögelerinin ders ortamına aktarılmasın nedenlerini şu şekilde sıralamıştır: olmak

* Öğrencilerin her insanın davranışında kültürün etkisi olduğunu anlamalarına yardımcı

* Öğrencilerin yaş, cinsiyet, sosyal sınıf gibi değişkenlerin insanların konuşmalarında ve davranışlarında etkisi olduğunu anlamalarına yardımcı olmak,

* Öğrencilerin hedef kültürdeki ortak durumlarda gösterilen ortak davranışların farkına varmalarına yardımcı olmak.

* Öğrencilerin bazı sözcük ve tümceciklerin, kültürün bir sonucu olarak, hep aynı biçimde birbiri ardına geldiğinin farkına varmalarına yardımcı olmak. olmak.

* Öğrencilerin hedef kültürle ilgili genellemeleri nesnel gözle değerlendirmelerine yardımc1

* Öğrencilerin hedef kültürle ilgili bilgi toplama becerilerinin gelişmesine yardımcı olmak.

* Öğrencilerde hedef kültürle ilgili merak uyandırmak ve onların o kültürdeki insanlara empati duymalarını sağlamak.(Okur ve Keskin,2013) 
$\mathrm{Bu}$ kültürel kavramların başında o dilin mensup olduğu milletin değerleri gelmektedir. Çünkü bir milletin değerleri, o millet hakkında çeşitli ipuçları vermekte ve o milletin yaşayış tarzını göstermektedir.

\section{Yöntem}

\section{Araştırmanın modeli}

Çalışmada nitel araştırma yöntemlerinden betimsel tarama modeli kullanılmıştır. Karasar'a (2006:77) göre tarama modelleri geçmişte ya da hâlâ var olan bir durumu var olduğu şekilde betimlemeye çalışan bir yaklaşımdır. Bu modellerde herhangi bir değiştirme ve etkileme söz konusu değildir. Amaç bilinmek istenenin uygun bir biçimde gözlenmesidir.

\section{Örneklem}

$\mathrm{Bu}$ çalışmada uzman görüşünün alındığı dört Türkçe öğretmeni bulunmaktadır. Bu öğretmenlerin mesleki kıdemleri 8 ile 14 yıl arasında değişmektedir. Çalışmada uzmanlar, Yedi İklim $\mathrm{C} 1$ ve $\mathrm{C} 2$ düzeyi ders kitaplarında yer alan dinleme metinleri incelenmiştir. Yedi İklim C1 düzeyi ders kitabında 27, C2 düzeyi ders kitabında 27 olmak üzere toplamda 54 tane dinleme metni bulunmaktadır. Tablo 1'de C1 ve C2 düzeyindeki ders kitaplarında yer alan dinleme metinlerinin sayıları verilmiştir.

Tablo 1: Ders kitaplarında yer alan dinleme metni sayıs1

\begin{tabular}{|ll}
\hline & Dinleme Metni Sayıları. \\
\hline C1 Düzeyi & 27 \\
\hline C2 Düzeyi & 27 \\
\hline TOPLAM & 54 \\
\hline
\end{tabular}

Tablo 2: C1 Düzeyi Ders Kitabındaki İncelenen Dinleme Metinleri

\begin{tabular}{ll}
\hline 1- Olimpiyat Oyunlarında Yaşanmış İlginç Olaylar & 15- Maya Medeniyeti \\
2- Türkiye Destan Yazdı & 16- Sultan Şairler \\
3- Sporcular Nasıl Beslenir? & 17- Sempozyuma Ulaşım \\
4- Deveyle 22 Yıl Seyahat & 18- VI. Dünya Dili Türkçe Sempozyumu Açılış \\
& Konuşması \\
5- Uçuş Sendromu & 19- Kültürel Karşılaştırmalar Sempozyumu \\
6- Yakın Gelecek ve Yapay Zekâ & 20- Pablo Picasso ve 4 Rakamı \\
7- Dilin Tadı & 21- Satrancın Hikâyesi ve Üslü Sayılar \\
8- Yaşayan İnsan Değeri & 22- "Matematik” in Hayatımızdaki Yeri ve Önemi \\
9- Aşk Mektupları & 23- Türkiye Bursları \\
10- Hayvan Davranışlarının İnsandaki Görünümleri & 24- Sayıların Uğuruna İnanır mısınız? \\
11- Benzerlikler & 25- Barış Manço - Kazma \\
12- Çiçek Kültürü & 26- Karalamalar ve Karakter Tahlili \\
13- İsim Bulma Sanatı & 27- Bedeniniz Sizi Ele Veriyor \\
14- Dilimizi Yazıyoruz ve Okuyoruz & \\
\hline
\end{tabular}

Tablo 3’te ise C2 düzeyi ders kitabında incelenen metinler verilmiştir. 
Tablo 3: C2 Düzeyi Ders Kitabındaki İncelenen Dinleme Metinleri

\begin{tabular}{ll}
\hline 1- Emine Işınsu ile Edebiyat Üzerine Bir Söyleşi & 15- Diller Bir İstekler Ayrı \\
2- Turan Oflazoğlu ile Tarihî Bir Gün & 16- Nasrettin Hoca'nın Köyünde \\
3- Beyaz Gemi & 17- İletişim \\
4- Kadın Dediğin & 18- Beden Dili \\
5- Namdar Nami Karatay & 19- Üçüncü Şahsın Şiiri \\
6- Erkek Dediğin & 20- Etik Eğitimi ve İletişim Etiği \\
7- Düğmelerin Anlattığı Tarih & 21- Yapıcı Olmak \\
8- Doğu ve Batı'nın Estetik Algısındaki & 22- Annenin Gözüyle Evlat \\
Farklılıklar & \\
9- Aşk Mektupları & 23- Eski Bir Tapınak Yazıtı \\
10- Canım İstanbul & 24- Şavşat’ı Üstü Başı Kar \\
11- Atıl Kutoğlu & 25- Çorum’un Pazar Yerinde \\
12- Türkan Şıray'la Röportaj & 26- Yalnızlar \\
13- Evrenin Sırlarını Çözen İnsan & 27- Yapay Uydular \\
14- Kötü Bir Rüya mı Yoksa Kâbus mu? &
\end{tabular}

\section{Veri Toplama Aracı}

Söz konusu metinler alanında uzman dört kişi tarafindan "Değer İnceleme Formu"na (DİF) göre incelenerek dinleme metinlerinin hangi değerleri içerdiği tespit edilmeye çalışılmıştır. Çapoğlu (2014) tarafından geliştirilen Değer İnceleme Formu (DİF) oluşturulurken Güngör'ün (1993) değer sınıflandırmasından, Rokeach'nin (1973) araç değerler ve amaç değerler tablosundan, yararlanılmıștır. Oluşturulan formun Cronbach Alfa iç tutarlık katsayısı 0.768 olarak tespit edilmiştir (Çapoğlu, 2014: 56).

\section{Verilerin Analizi}

Araştırmacılar değer inceleme formuyla dinleme metinlerini incelemişlerdir. Birden fazla uzman olduğu için incelenen metinlerde bütün uzmanların ortak belirledikleri değerler "görüş birliği" kabul edilmiştir. Uzmanlar arasında ortak olarak belirlenmeyen değerler ise "görüş ayrıllı̆̆ı" olarak kabul edilmiştir. 62 değeri uzmanlar ortak olarak belirttikleri için "görüş birliği" olarak 13 tane değeri ise ortak olarak belirmedikleri için "görüş ayrılığı" şeklinde kabul edilmiştir. Miles ve Huberman'ın (1994) belirtmiş olduğu görüş birliği/görüş birliği+görüş ayr1lığ1 formülüne göre uzlaşma yüzdesi 0.82 olarak bulunmuştur. Uzlaşma yüzdesinin Karasar'a (2006: 165) göre 0.75'ten küçük olmas1 güvenirlik açısından sıkıntı doğurmaktadır.

\section{Bulgular ve Yorum}

Tablo 4'te ise incelenen 27 adet metinde bulunan değerler verilmiştir. 27 adet metinde toplam 29 adet değer bulunmuş olup metinlerde en fazla yer alan değerin "çalışkanlık" olduğu görülmüştür. En az yer verilen değerler: misafirperverlik, görgü kurallarına uyma, Türk büyüklerine sayg1, vatanseverlik ve milli bilinçtir. Tabloda da görüldüğü gibi 13 farklı değer başlığı görülmektedir. Bu durum kitaplarda istenen bir durumdur. Çünkü kitaplarda sadece bir değerin baskın olmasından ziyade birçok değerin bulunması değerlerin aktarımı yönünden çok daha etkilidir 


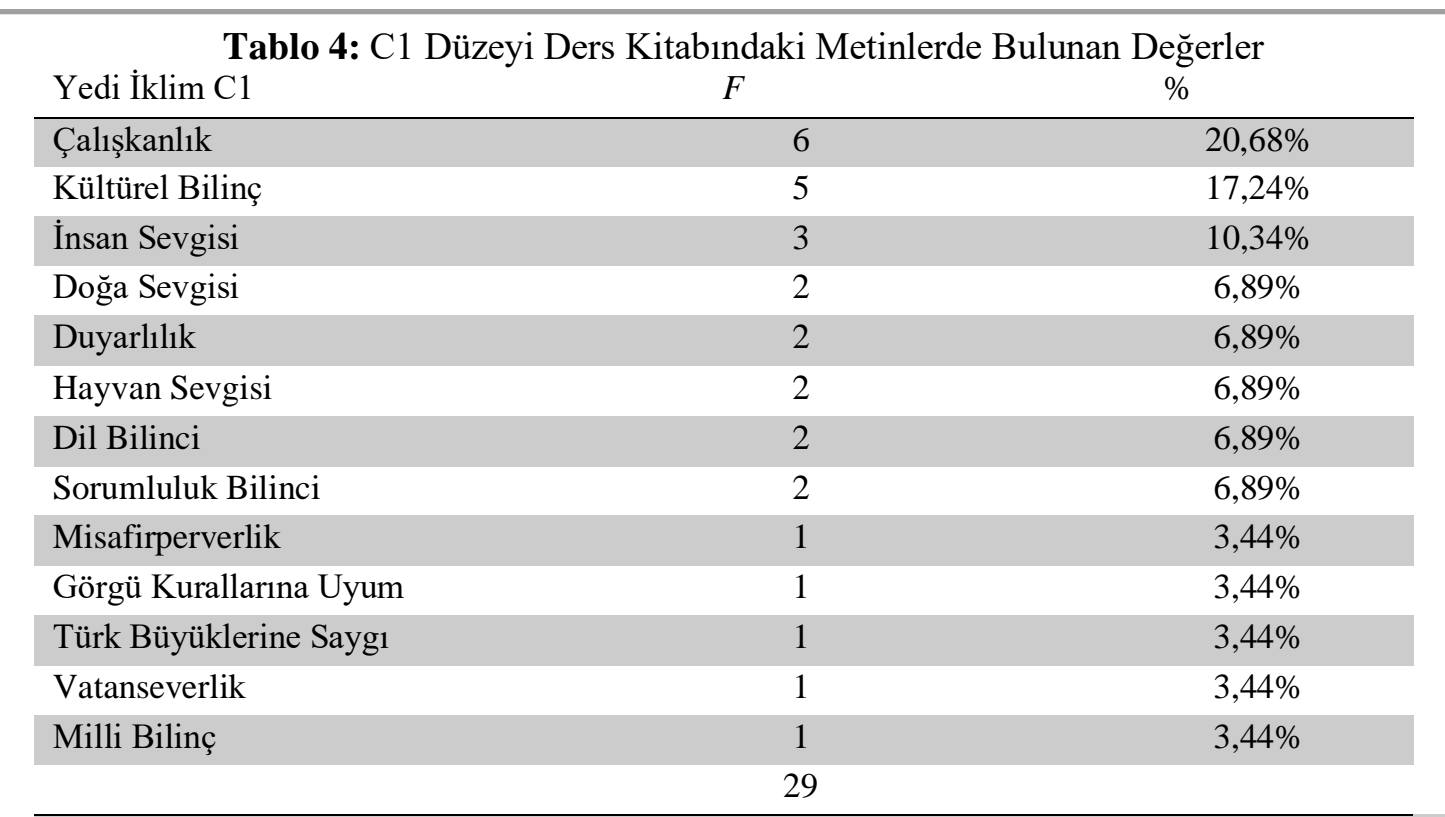

Tablo 5'te incelenen 27 adet metinde bulunan değerler verilmiştir. 27 adet metinde toplam 34 adet değer bulunmuş olup metinlerde en fazla yer alan değerin "insan sevgisi" olduğu görülmüștür. En az yer verilen değerler: sorumluluk bilinci, yardımseverlik, Türk büyüklerine sayg1, hoşgörülü, toplumsal kurallara uyum, dürüstlük, vatanseverlik ve akılcılıktır. Tabloda da görüldüğü gibi 15 farklı değer başlı̆̆ görülmektedir. Bu durum kitaplarda istenen bir durumdur. Çünkü kitaplarda sadece bir değerin baskın olmasından ziyade birçok değerin bulunması değerlerin aktarımı yönünden çok daha etkilidir.

Tablo 5: C2 Düzeyi Ders Kitabındaki Metinlerde Bulunan Değerler

\begin{tabular}{lcc} 
Yedi İklim C2 & $F$ & $\%$ \\
\hline İnsan Sevgisi & 7 & $20,58 \%$ \\
Kültürel Bilinç & 6 & $17,64 \%$ \\
Çalıškanlık & 3 & $10,34 \%$ \\
Doğa Sevgisi & 3 & $8,82 \%$ \\
Büyüklere Sayg1 & 3 & $8,82 \%$ \\
Aile Bilinci & 2 & $5,88 \%$ \\
Dil Bilinci & 2 & $5,88 \%$ \\
\hline Sorumluluk Bilinci & 1 & $2,94 \%$ \\
Yardımseverlik & 1 & $2,94 \%$ \\
Hoşgörülü & 1 & $2,94 \%$ \\
\hline Toplumsal Kurallara Uyum & 1 & $2,94 \%$ \\
Dürüstlük & 1 & $2,94 \%$ \\
\hline Türk Büyüklerine Saygı & 1 & $2,94 \%$ \\
Vatanseverlik & 1 & $2,94 \%$ \\
Akılcılık & 1 & $2,94 \%$ \\
\hline
\end{tabular}


$\mathrm{C} 2$ düzeyindeki dinleme metinlerine bakıldığında $\mathrm{C} 1$ düzeyine göre hem daha fazla değer başlı̆̆ hem de daha fazla değer bulunduğu görülmektedir. C1 düzeyinde 13 farklı değer başlığ ve toplam 29 tane değer bulunurken C2 düzeyinde ise 15 farklı değer başlığı altında toplam 34 tane değer bulunmaktadır.

Tablo 6'da $\mathrm{C} 1$ ve $\mathrm{C} 2$ düzeyinde yer alan toplam 54 dinleme metninin değerleri bir arada verilmiştir. Bu düzeylerde incelenen 54 adet metinde 63 adet değer bulunmuştur. Bu kitaplarda en fazla yer alan değerlerin "kültürel bilinç, insan sevgisi ve çalışkanlık" olduğu görülmüştür. Bu üç değer kitaplarda yer alan değerlerin yaklaşık yarısına (47,61\%) denk gelmektedir. Dinleme metinlerinde en fazla kültürel bilincin yer verilmesi çok önemlidir. Çünkü çalışmanın başında da belirtildiği gibi bir dili öğretmek için o dile ait kültür unsurlarının da verilmesi gerekmektedir.

Tablo 6: $\mathrm{C} 1$ ve C2 Düzeyi Ders Kitabındaki Metinlerde Bulunan Bütün Değerler

\begin{tabular}{lcc} 
Yedi İklim C1 ve C2 & \multicolumn{1}{l}{$\%$} \\
\hline Kültürel Bilinç & 11 & $17,46 \%$ \\
\hline İnsan Sevgisi & 10 & $15,87 \%$ \\
\hline Çalıs̆kanlık & 9 & $14,28 \%$ \\
\hline Doğa Sevgisi & 5 & $7,93 \%$ \\
\hline Dil Bilinci & 4 & $6,44 \%$ \\
\hline Büyüklere Saygı & 3 & $4,76 \%$ \\
\hline Sorumluluk Bilinci & 3 & $4,76 \%$ \\
\hline Aile Bilinci & 2 & $3,17 \%$ \\
\hline Duyarlılık & 2 & $3,17 \%$ \\
Hayvan Sevgisi & 2 & $3,17 \%$ \\
\hline Türk Büyüklerine Saygı & 2 & $3,17 \%$ \\
\hline Vatanseverlik & 2 & $3,17 \%$ \\
\hline Akılcılık & 1 & $1,58 \%$ \\
\hline Dürüstlük & 1 & $1,58 \%$ \\
\hline Görgü Kurallarına Uyum & 1 & $1,58 \%$ \\
\hline Hoşgörülü Olma & 1 & $1,58 \%$ \\
\hline Milli Bilinç & 1 & $1,58 \%$ \\
\hline Misafirperverlik & 1 & $1,58 \%$ \\
\hline Toplumsal Kurallara Uyum & 1 & $1,58 \%$ \\
\hline Yardımseverlik & 1 & $1,58 \%$ \\
\hline
\end{tabular}

\section{Sonuç ve Öneriler}

Dünya hızlı bir değişimin içindedir. Özellikle teknoloji alanındaki ilerlemeler bu gelişimin en büyük nedenlerinden biridir. Artık birçok haberleşme aracıyla insanlar kendilerinden binlerce kilometre uzaklıktaki olayları görmekte ve bilmektedir. İnsanların kendilerinden farklı toplumları, ülkeleri vb. görmeleri; dil öğrenmeye ve dil öğretmeye olan dikkati daha da artırmıştır. Ayrıca gelişen dünya şartlarında insanlar gerek eğitim gerekse iş için çeşitli yerleri ziyaret etmekte ve çeşitli toplumları görüp tanımaktadır. Son yıllarda ülkemiz de bu konuda bir hayli dikkatleri üzerine çekmektedir. Çünkü farklı ülkelerdeki insanların eğitim ve iş amacıyla Türkiye'yi ziyaret ettikleri görülmektedir. Yabancı dil öğretimi alanında ilkelerin en önemlilerinden biri, dil ile birlikte kültürün de aktarılması ilkesidir (İnce, 2018:152). Bu bağlamda dil öğretimi aynı zamanda kültür öğretimidir. Kültür ise toplumun üzerinde fikir birliğine vardığı ortak değerlerin bütünüdür. Jiang (2000), dil ve kültürün bir buzdağına benzetildiğinden; buzdağının görünen kısmının dil, suyun altında kalan 
kısmının ise kültürün görünmeyen parçaları olduğundan bahsetmektedir (Boztilki, 2018:756). Kültürün en önemli ögelerinden biri değerlerdir. Değerler bir toplumun yapı taşlarıdır. Bu yapı taşlarına bakılarak o toplum hakkında çeşitli fikirler elde edilebilir. Bu yüzden bir toplumun değerlerini bilmek, o toplumun kültürünü tanımaktır. Kültür tanındığında ise o toplumun dilini öğrenmek çok daha kolay olacaktır. Çalışmada Yedi İklim C1 ve C2 düzeyi ders kitaplarında yer alan dinleme metinlerinde yer alan değerler araştırılmıştır. Bu kitaplarda yer alan dinleme metinlerinin araştırılmasının nedeni daha önce yapılan çalışmalarda çoğunlukla okuma metinlerinin araştırılmasıdır. Çalışma bu yönüyle bir ilktir. İki farklı düzeyde toplam 54 tane dinleme metni incelenmiş ve 28 farklı değer başlığında toplam 63 değer bulunmuştur. En fazla bulunan değerler: kültürel bilinç, insan sevgisi ve çalışkanlıktır. İncelenen dinleme metinlerinde yer alan değerlerin kuramsal çerçevede bahsedilen değer sinıflandırmalarıyla paralel olduğu görülmüştür. Bu çalışmada $\mathrm{C} 1$ ve $\mathrm{C} 2$ düzeyi ders kitaplarında yer alan dinleme metinlerindeki değerler incelenmiştir. Bundan sonraki çalışmalarda farklı düzeylerde ders kitaplarında yer alan dinleme metinlerindeki değerler incelenebilir. Bu çalışmada uzmanların görüşlerine göre değerler incelenmiş olup metinler öğrenciler tarafından da incelenebilir. Ayrıca farklı metinlerde yer alan değer sıklıkları incelenebilir. Farklı düzeydeki ders kitaplarındaki metin türleriyle birlikte metin türlerinde yer alan değerler de incelenebilir.

\section{Kaynakça}

Akbaş, O. (2004). Türk milli eğiitm sisteminin duyuşsal amaçlarının ilköğretim II. kademede gerçekleşme derecesinin değerlendirilmesi. Doktora tezi. Gazi Üniversitesi Eğitim Bilimleri Enstitüsü.

Akyol Gürler, Ş. \& Aydın, M.Z. (2014). Okulda Değerler Ĕ̈itimi, Yöntemler, Etkinlikler, Kaynaklar. Nobel Akademi Yayıncilik.

Boztilki, G. (2018). Gazi Üniversitesi Tömer B1 Seviyesi Kitabının Değerler Eğitimi Açısından İncelenmesi. International Journal of Human Sciences, 755-765.

Çapoğlu, E. (2014). Ortaokul 8. Sinıf Ders Kitaplarındaki Şiirlerde Yer Alan Değerler. Yüksek lisans tezi. Sakarya Üniversitesi Eğitim Bilimleri Enstitüsü

Erdal, K. (2018). Yabancılara Türkçeyi Öğretirken Türkiye’yi Öğretmek: Ulutömer Örneği. Uludă Üniversitesi Eğitim Fakültesi Dergisi, 81-94.

Gültekin, İ., Kalfa, M., Mete, F., Eryiğit, A., Kılıç, U., \& Gönültaş, G. (2016). Yedi İklim Türkçe C2 Dinleme Metinleri. Yunus Emre Enstitüsü.

Gültekin, İ., Kalfa, M., Mete, F., Eryiğit, A., Kılıç, U., \& Gönültaş, G. (2017). Yedi İklim Türkçe C1 Dinleme Metinleri. Yunus Emre Enstitüsü.

Güngör, E. (2000). Değerler Psikolojisi Üzerine Araşstırmalar. Ötüken Yayıncılık.

İşcan, A., \& Yassıtaş, T. (2018). Yabancı Dil Olarak Türkçe Öğretimi Ders Kitaplarında Kültür Aktarımı: Yedi İklim Türkçe Öğretim Seti Örneği (B1-B2 Düzeyi). Aydın Tömer Dil Dergisi, 47-67.

Kalfa, M. (2013). Yabancılara Türkçe Öğretiminde Sözlü Kültür Unsurlarının Kullanımı. Milli Folklor, 167-177.

Karasar, N. (2006). Bilimsel Araştırma Yöntemleri. Nobel Akademi Yayıncılık.

Kuşdil, M. E., \& Kâğıtçıbaşı, Ç. (2000). Türk Öğretmenlerin Değer Yönelimleri ve Schwartz Değer Kuram1. Türk Psikoloji Dergisi, 59-76. 
Okur, A., \& Keskin, F. (2013). Yabancılara Türkçe Öğretiminde Kültürel Ögelerin Aktarımı: İstanbul Yabancılar için Türkçe Öğretim Seti. The Journal of Academic Social Science Studies, 1619-1640. 